\title{
Съвременни аспекти в патогенезата и лечението на шума в ушите
}

\author{
Зл. Желязкова', Р. Бенчев, М. Милков² \\ ${ }^{1}$ Медицински институт - МВР - УНГ-клиника \\ ${ }^{2}$ Медицински университет - Варна, Факултет по дентална медицина
}

\begin{abstract}
:
Tinnitus is the medical term for the auditory perception of sounds in the absence of surrounding sounds. Tinnitus may be the only or most important symptom, or it may be a component of an otovestibular complaint (impaired hearing, distortion of sound, recruitment, sensation of pressure or pain in the ear, vertigo, instability or blurred vision). Tinnitus can be accompanied by unpleasant sensations and be associated with anxiety and depression. Anatomical and physiological evidence provides the substrate for somatosensory influences on both the generation and modulation of tinnitus. Tinnitus can no longer be considered an exclusive disorder of the auditory system, but it is rather an expression of neural plasticity encompassing reactions of multisensory neurons to changes in their external environment. There are different and new methods of testing the tinnitus, including psycho physiological ones. The treatment of this symptom is very difficult. There is no specific therapy, but it should be etiologically defined and complex.
\end{abstract}

\section{Резюме:}

Шумът в ушите е медицински термин за слухово възприятие на звуци при липсата на такива в обкръжаващия свят. Тинитусът може да бъде единственият или най-важният симптом или компонент на заболяване на слухово-вестибуларната система (нарушение на слуха, дисторзия на звука, рекруитмент, чувство на тежест или болка в ухото, световъртеж, нестабилност или замъглено виждане). Шумът в ухото може да бъде придружен с неприятни усещания, безпокойство или депресия. Анатомични и физиологични доказателства установяват наличие на соматосензорно влияние върху произхода и модулацията на тинитуса. Шумът в ухото може да не бъде повече смятан предимно за увреда на слуховия анализатор, но повече се смята за проява на неврална реакция на мултисензорните неврони спрямо дразнения от външната среда. Има нови различни методи за изследване на тинитуса, включващи и психо-физиологични такива. Лечението на шума в ухото е изключително трудно. Няма специфична терапия, но лечението би трябвало да е етиологично дефинирано и комплексно.

\section{Дефиниция}

Тинитусьт е медицински термин за перцепция на звук или шум в отсъствие на акустична стимулация. Терминът произлиза от латинската дума за звънене „tinnere“. Слуховото възприятие за тинитус е изключително разнообразно, като включва: жужащ, свиркащ, брьмчащ, бучащ звук. Тинитусьт може да бъде: слаб, среден или силен; остро проявяващ се или хроничен; нискочестотен или високочестотен; постоянен или периодичен; пулсиращ или ритмичен; да се усилва в тиха или в шумна среда; да се чува в едното ухо, в двете уши или в цялата глава; с различни вариации през нощта и през деня; компенсиран - да не пречи на работоспособността, или декомпенсиран - да пречи на качеството на живот и работа. Шумът в ухото може да е синхронен с ударите на сърцето или с дишането. Тинитусьт може да е единствен симптом или да е част от отологични и отоневрологични оплаквания като намален слух, неправилно възприятие на звука, рекруитмант, чувство на тежест и болка в ухото, световъртеж, нестабилна походка и др. Шумът в ухото може да се съчетава или да предизвиква психологични и психиатрични симптоми като главоболие, раздразнителност, потиснатост, безпокойство, депресия. Тинитусьт трябва да бъде отдиференциран от слуховата халюцинация на думи, звуци или песни, симптом, характерен за психиатрични заболявания. Хиперакузисът или звуковата и шумова нетолерантност може да съпьтства тинитуса. Пациентите с хиперакузис се оплакват от дискомфорт към възприемане на различни звуци 
и особено болезнена чувствителност към високи звуци. Хиперакузисьт трябва да се отдиференцира от рекруитмана, който представлява възприятие на абнормно бързо увеличение на гръмкостта на звуците. (1)

\section{Патогонеза и етиология}

Обикновено се смята, че тинитусът се заражда в кохлеята и е симптом на налично отологично заболяване. Новите проучвания обаче показват, че произходът на шума в ушите са централните слухови пътища и слуховата зона на мозъка. За да се докаже тази теория, изследователите са използвали електрофизиологични изследвания на експериментален животински модел за съставяне на карта на мозъчната активност чрез невроскениране; както и проследяване на мозъчната невронна активност при пациенти с предизвикан тинитус. (2) Проучванията показват висока степен на ангажираност на слуховите пътища и тяхната връзка с кохлеарната дисфункция при пациенти с тинитус. Имуноцитохимичните изследвания показват компенсаторно увеличение на глутаматергичната инервация. Изследвани са 1500 пациенти на възраст от 26 до 45 години, страдащи почти 5 години от хроничен шум в ушите. (3) Резултатите показват комбинация от променена слухова еференция и слухова корова зона и кохлеарна дисфункция като причина за предизвикване и стимулиране интензитета на тинитуса (Фиг. 1). При експериментално предизвикан тинитус функционалният ЯМР показва активност на слуховата зона на мозъчната кора, кохлеарните ядра, colliculus inferior. (8). При едностранно предизвикан тинитус реагират ипсилатералният corpus geniculate mediale и контралатералният colliculus inferior, както и контралатералното кохлеарно ядро.

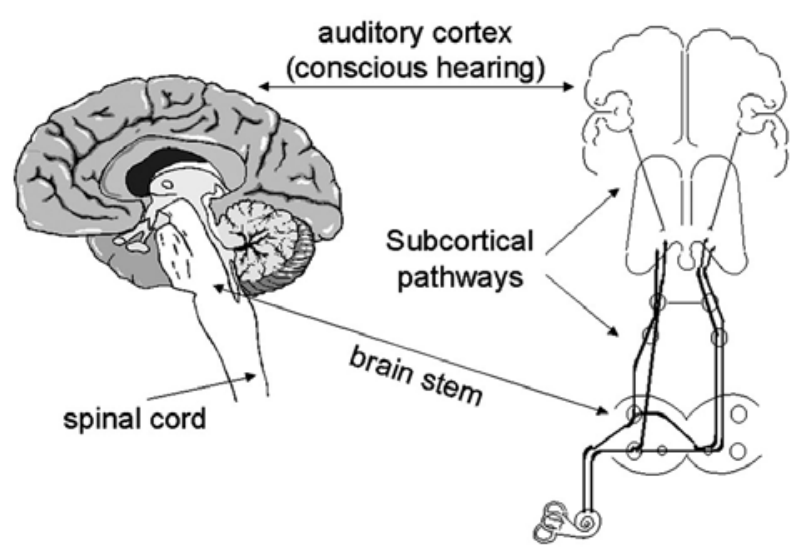

Фиг. 1.

Измерените слухови стволови потенциали на пациенти с тинитус показват и засягане на лим- бичната система. (3) Тези изследвания доказват патогенетичната връзка между тинитуса и емоционалните разстройства като безпокойство, депресивни състояния, раздразнителност, безсъние. Неврофизиологичният модел показва два пьтя на връзка на слуховия анализатор с лимбичната и с автономната нервна система. Горният нервен сноп ангажира съзнанието, а долният - подсъзнанието. (9) Теоретично активността на симетрични части от автономната нервна система, които се смятат за отговорни за отрицателни шумово предизвикани реакции, може да бъде следствие на горния и долния нервен сноп. Когато има наличност на хронична форма на тинитус, активността на автономната система се предизвиква от доминиране на долния сноп, т.е. на подсъзнанието. Когато е налице остра форма на тинитус, доминира активността на горния сноп, т.е. на съзнанието. $(4,5)$ (Фиг. 2).

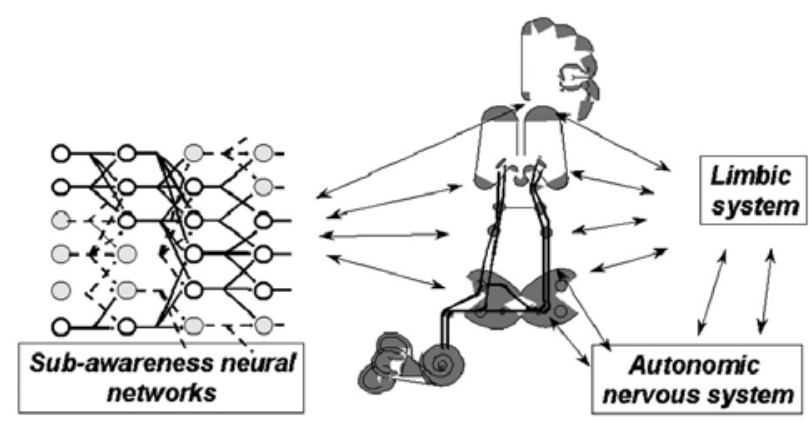

Фиг. 2.

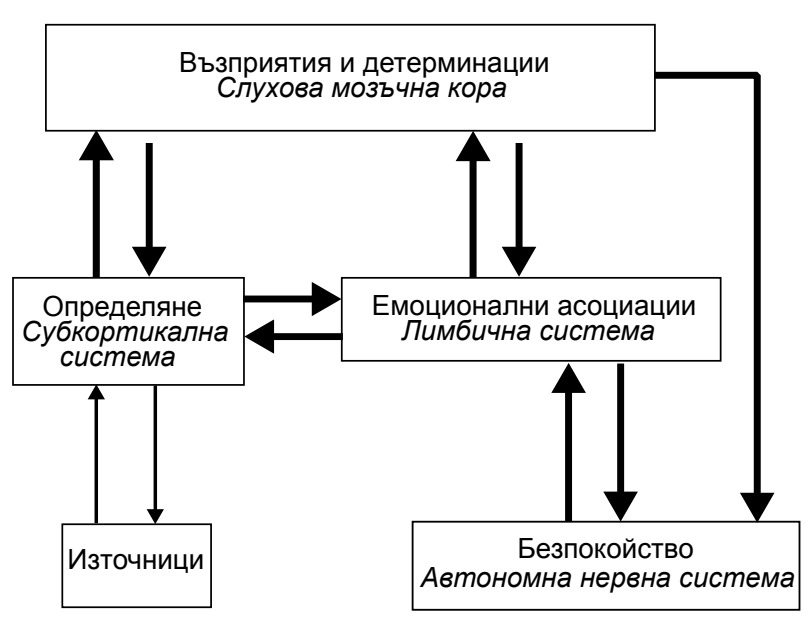

Фиг. 3.

Нарастват клиничните доказателства за връзката на соматосензорната система с тинитуса. Често характеристиките на шума в ушите могат да се променят от соматична модулация. Протрузия или дислокация на долната челюст могат да предизви- 
кат тинитус. Тези ефекти се базират на невронна връзка между соматосензорната система и слуховия анализатор. Съществуват невронни връзки между двете кохлеарни ядра, colliculus inferior и ganglion trigeminale и слуховата зона на мозъчната кора. Ефектьт на соматосензорната система върху слуховата система и появата на тинитус може да бъде регистриран чрез функционален ЯМР на централната част на слуховия анализатор. Соматосензорният импулс предизвиква дразнене на слуховите пътища, включващи кохлеарните ядра и слуховата мозъчна кора. Допълнително са направени ЕМГ изследвания на мускулите, ангажирани в движението на темпоромандибуларната става. Когато има деформация на ставата и тинитус, функционалният ЯМР показва повишена активност на невроните на малкия мозък, вентролатералното ядро на таламуса, слуховите ядра, слуховата зона и моторната област на кортекса. (6) Чрез функционалния ЯМР се наблюдават три вида различни невронни отговора при пациенти с тинитус:

- увеличена активност на невронния отговор от страна на слуховата зона на мозъчната кора, свързано с отчитане на хиперакузис;

- увеличение на разпространението на невронната активност, свързано с отчитане на шум в ушите;

- увеличение на активността на невроните в амигдалата, свързано с наличие на раздразнителност и безпокойство. (7)

Съвременните проучвания на популация от хора между 55 и 65 години показват наличие на $12 \%$ пациенти с тинитус, като $2 \%$ от тях съобщават за нарушения на режима на бит и работа и смутено качество на живот. (1) Два са основните категории шум в ушите: обективен - този, при който има наличие на реален звук, и субективен - фантомно усещане за звук. Причините за обективния тинитус могат да бъдат:

- оклузия на външния слухов проход;

- дехисцентен полуокръжен канал;

- васкуларна етиология: стеноза или дисецираща аневризма на art. carotis, артериален луп във вътрешния слухов проход, артерио-венозна малформация, glomus tympanicus, хипертония, palatoclonus, контракция на m.tensor tympani, цервикоартроза и последващ смутен кръвоток при завьртване на главата.

Субективният тинитус е постоянен и се предизвиква от дисфункция на периферната и централна част на слуховия анализатор. Смята се, че хипе- рактивността на кортикалните гама-неврони в слуховата зона на мозъчната кора е невралният код на тинитуса. Според много автори шумът в ушите се смята за слухов фантомен феномен, подобен на фантомната болка. Тинитусьт се предизвиква от реорганизация на централните слухови пътища и слуховата кора, като е налице липса на супресия на невронната активност. Причините, които могат да доведат до поява на субективен шум в ушите, са следните:

- въздействие на силен шум - битов или производствен;

- отологични заболявания с проводно намаление на слуха - cerumen, otosclerosis, otitis serosa;

- заболявания с невросензорно намаление на слуха- перманентна шумова травма, Мениерова болест, презбиакузис, автоимунни заболявания на вътрешното ухо, генетична невросензорна глухота, лабиринтит или кохлеит;

- ретрокохлеарна невросензорна слухова загуба или патология на понтоцеребеларния ьгъл - кохлеовестибуларен компресивен синдром, neurinoma acoustici;

- дисфункция на ствола и слуховата кора - мозъчен тумор, лезии на бялото мозъчно вещество;

- общи или фокални кортикални дисфункции, включително депресия;

- токсикологични или фармакологични ефекти;

- соматични заболявания - цервикална патология, дисфункция на темпоромандибуларната става.

Обобщено субективният шум може да се групира по следния начин:

1. Физиологичен тинитус.

2. Тинитус с кохлеарен произход. При този вид е налице продължителна по-висока възбудимост на вътрешните ресничести клетки, както при високо шумово въздействие.

3. Тинитус, свързан с невросензорно намаление на слуха. Загубата на слуха води до спадане на периферния неврален отговор и повишаване на кортикалната хиперактивност, което води до функционални промени в слуховата кортикална област. Този тип тинитус се описва като „слухово фантомно усещане“" и се асоциира с тонотопна реорганизация на кортикалната карта. Намалението на латералното инхибиращо заглушаване има сьпьтстващ ефект на намален кохлеарен отговор.

4. Тинитус със соматичен произход. Соматосензорната модулация на слуховата система може да бъде предизвикана от дисторзия на манди- 
буларната става, дисфункция на масетрите и остеохондроза на шийните прешлени.

5. Последният вид тинитус включва дисфункция или лезия в ствола или централната нервна система. Трудно диагностирана, но важна патология е кохлеовестибуларният компресивен синдром. При него има връзка между кръвоносните съдове, които са в близост до кохлеовестибуларната система и лицевия нерв. Тинитусът при този синдром прилича на шум от клавиатура на стара пишеща машина. Патогенезата включва васкуларен конфликт в сегмента на осмия черепномозъчен нерв в областта на вътрешния слухов проход. Отделен механизъм включва лимбичната система. Този вид тинитус е описан в литературата като неврофизиологичен модел на Jastreboff. Суперселективна фармакологична анестезия и невроизображението на амигдалохипокампа демонстрира разстройство на лимбичната система при пациенти с тинитус.

\section{Методи на изследване}

Анамнезата трябва да включва данни за внезапно или прогресивно начало на симптома; продължителност и сила на тинитуса; едностранно, двустранно или в цялата глава се проявява; с ниска или висока тоналност е; флуктуиращ, пулсиращ или постоянен. Освен оториноларингологичния и отоневрологичния преглед трябва да се изследва вратната мускулатура и функцията на темпоромандибуларната става. Аудиологичното изследване включва: тонална прагова аудиометрия, импедансметрия, отоакустични емисии, високочестотна аудиометрия, слухови стволови евокирани потенциали. $50 \%$ от пациентите с тинитус над 50 години и $21 \%$ от пациентите под 50 години показват лезии в бялото мозъчно вещество и невроваскуларни проблеми при ЯМР. Необходимо е и психофизикалното изследване на шума чрез използване на визуалноаналогова скала от 0 до 10 и различни по вид выпросници (THI, THQ, TRQ, $\mathrm{TQ})$, които са свързани с определяне степента и тежестта на шума в ушите и влиянието му върху качеството на живот, бита и работоспособността на пациента, наличието на депресивни симптоми, раздразнителност, безсъние. Най-разпространен в практиката е выпросникът на R. Hallam и сътр., изд. 1988 и преработен 1996 г. Психоакустичните характеристики на шума включват латерализация при едностранен тинитус и комбинация на различни честоти при двустранен тинитус; височината на шума в $\mathrm{dB}$ HL; заглушаване на шума и резидуална инхибиция. Някои от тях могат да бъдат изслед- вани аудиометрично. Под внимание трябва да се вземат факторите, които влияят върху силата и грьмкостта на шума като: контракцията на шийните мускули, стрес, силен шум, физическо натоварване, наличие на ринит, синуит или фарингит, умора, употреба на кафе, алкохол, солена диета и тютюнопушене, вредно влияние на обкръжаваща социална среда.

Съществуват два нови съвременни специални тестове за определяне на шума:

- Електрическа транстимпанална стимулация на промонториума. Тестът определя дали електричната стимулация на промонториума може да повлияе тинитуса. Тестьт се осъществява чрез електрокохлеография. Чрез електрод от 0 до $500 \mu \mathrm{A}$ се подава звук между 50 и 1600 Hz. Пациентът показва дали възприема звука и дали има промяна в усещането за шума.

- Транскраниална стимулация чрез магнитно поле. Целта е да се потисне кортикалната хиперактивност и придружаващия я шум. Силно пулсиращо магнитно поле селективно се поставя върху проекцията на слуховата зона на мозъчната кора. Процедурата се използва и за намаляване силата на шума. Когато се постави апарата върху главата, се смята, че магнитното поле действа на 3 см в диаметър и между 2 и 3 см в дълбочина.

\section{Лечение}

Лечението на тинитуса, особено на хроничната форма, е сложно, комплексно и включва широка гама от фармакологични, психосоматични, хирургични и физиотерапевтични подходи. Понастоящем няма специфична терапия за хронична форма на тинитус, която да е удачна за всички пациенти.

1. Медикаментозното лечение включва:

- вазодилататори, антиспазмолитици, антихистамини;

- невротрансмитори, Са- антагонисти;

- локални анестетици;

- седатива - бензодиазепини, антиконвулсивни, антидепресанти.

2. Тинитус маскер или генератор - особено подходящи в съчетание със слухова протеза при наличие на невросензорна загуба на слуха и тинитус.

3. Хирургично лечение - интратимпанална апликация на Gentamycin, кортикостероиди или лидокаин.

4. Транскраниална магнитна или електрична стимулация - неинвазивен метод, който позволява 
локално моделиране на кортикалната активност.

5. Психологичните методи включват терапевтични сеанси, релаксация, хипноза, лечение на стреса; привикване към тинитуса - подходящо при наличие на този симптом при дефинитивна глухота, тумори, централно мозъчни заболявания.

\section{Литература:}

1. P. Van de Heyning, O. Meeus, C. Blaivie, K. Vermiere, A. Boudewyns, D. DeRidder. Tinnitus: a multidisciplinary Clinical approach. B-ENT, 2007, 3 Suppl. 7, 3-10.

2. Shore Susan, Koehler,Seth, Dehmel Susanne, Zeng Chunhua. Neural basis of somatosensory influence on tinnitus. IX International Tinnitus Seminars. Abstract book..

3. Attias Joseph. Hearing and Tinnitus: Psychoacoustical and Neurophysiological Measures of Chronic Tinnitus. IX International Tinnitus Seminars. Abstract book..

4. Erlandsson Soly. Psychological Therapy for Tinnitus- Has it Fulfilled its Promises. IX International Tinnitus Seminars. Abstract book.

5. Jastreboff Pawel. The Role of Subconscious Pathwaws in Tinnitus and Decreased Sound Tolerance. IX International Tinnitus Seminars. Abstract book.

6. Lanting Cris, de Kleine Emile, van Dijk Pin. Somatosensory Interaction in the Auditory Pathway in Humans, an fMRI Study. IX International Tinnitus Seminars. Abstract book.
6. Музикалната терапия включва маскиране на шума, отклоняване на вниманието. Звуците могат да се използват в свободно слухово поле или чрез слухови протези. Музикотерапията може да включва звуци с честотата на шума, може да са с комфортна честота или със специфична.

7. Hebert Sylvie, Norena Arnaud, Fournier Phillipe,Zatorre Robert. Brain Mechanisms in Tinnitus and Hyperacusis: An fMRI study. IX International Tinnitus Seminars. Abstract book.

8. Marev, D., Vestibulo-cochlear disturbances in the course of vasoneural conflict of vestibule-cochlear nerve-diagnostic and therapeutic problems. "Final Programme and Abstract Book" PO-66, P: 80, IX ${ }^{\text {th }}$ International Tinnitus Seminars to be held in Goteborg, Sweden, 15-18 of June 2008

9. Marev, D., Patient-based outcomes in patients with primary tinnitus undergoing tinnitus retraining therapy. "Final Programme and Abstract Book" PO-67, P: 80, IX ${ }^{\text {th }}$ International Tinnitus Seminars to be held in Goteborg, Sweden, 15-18 of June 2008.

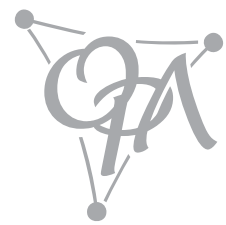

